\title{
Association between Socio-Demographic Factors and Blood Sugar Levels in Type 2 Diabetes Mellitus Patients in Bangladesh
}

\author{
Md. Rabiul Islam \\ Department of Clinical Pharmacy and Pharmacology, Faculty of Pharmacy, University of Dhaka, Dhaka, Bangladesh \\ Email: robi.ayaan@gmail.com
}

How to cite this paper: Islam, Md.R. (2017) Association between Socio-Demographic Factors and Blood Sugar Levels in Patients with Type 2 Diabetes Mellitus in Bangladesh. Journal of Diabetes Mellitus, 7 , 151-159.

https://doi.org/10.4236/jdm.2017.73012

Received: July 12, 2017

Accepted: August 8, 2017

Published: August 11, 2017

Copyright $\odot 2017$ by author and Scientific Research Publishing Inc. This work is licensed under the Creative Commons Attribution International License (CC BY 4.0).

http://creativecommons.org/licenses/by/4.0/

\begin{abstract}
Background: The aim of the current study was to evaluate the anthropometric and demographic factors and their correlation with type 2 diabetes mellitus (T2DM) in Bangladesh. Methods: One hundred fourteen patients (70 males and 44 females) between 30 and 75 years of age from various areas of Bangladesh were screened for T2DM. Fasting blood sugar (FBS) was analyzed by using laboratory kits and spectrophotometric technique. Anthropometric and socio-demographic data were collected using a structured questionnaire. Body mass index (BMI) was calculated from weight $(\mathrm{kg})$ and height $(\mathrm{m})$ of the individual respondents. Physical activity was categorized based on activity during daily work. Economic condition is defined by respective family income and education level is categorized into 3 levels: illiterate, 0 - 12 years of education and graduate or above. Results: According to the current study results, half of the patients were from the middle-class family with low physical activity and their age was within the range of 30 - 45 years. The male and female ratio of the study population was 60:40. Most of the patients were found to be obese and educated. Urban populations were more prone to have DM than the rural population. Age, education, the area of residence (urban and rural), physical activity and co-morbid diseases were significantly correlated with T2DM in Bangladesh $(\mathrm{P}<0.05)$. Conclusion: Our study shows that different socio-demographic factors have a significant correlation with T2DM in Bangladesh. Diabetes awareness, early diagnosis, patient education and life-style modification can be initiated to manage T2DM efficiently.
\end{abstract}

\section{Keywords}

Socio-Demographic Factors, Diabetes Mellitus, Association, T2DM, Blood Sugar Level, Bangladesh 


\section{Introduction}

Diabetes mellitus (DM) is a condition that adversely affects the normal physiological ability to produce or utilize insulin. Insulin is a hormone which is secreted by the pancreas and helps to carry glucose from the bloodstream into the cells [1]. Elevated blood sugar level is found in diabetes that can cause severe short-term and long-term consequences ranging from brain injury to amputations and heart disease [2]. So, diabetes mellitus is one of the heterogeneous carbohydrate metabolism disorders where defects occur in insulin secretion and utilization.

Globally, an estimated 422 million adults have DM as per the updated information from the World Health Organization (WHO) in 2016. That is one person is suffering from DM in every eleven people. Diabetes may lead to developing long-term complications in many parts of the body that increase the risk of premature death. The global prevalence of diabetes has almost doubled since 1980 , increasing from $4.7 \%$ to $8.5 \%$ among the adult people. Overweight or obesity is the associated risk factors for developing type 2 diabetes mellitus (T2DM) [3]. It is predicted that 592 million people will be affected by diabetes by 2035 globally [4]. Bangladesh holds the $2^{\text {nd }}$ position based on the number of diabetes patients among South Asian countries (5.1 million adults, 6.31\%). World Diabetes Day (WDD) increases awareness of the medical community, public health officials and the general public that DM is a rising public health problem [5]. Worldwide, DM is regarded as one of the most complex chronic diseases. T2DM is the $7^{\text {th }}$ leading cause of morbidity and mortality in the USA. Persons with diabetes require life-long personal care to decrease the chance of developing long-term complications. Good knowledge about the risk factors of diabetes including age, gender, educational level, the area of residence, BMI, and obesity, family history, and inactive life-style, plays an essential role in prevention and treatment [6]. Also, financial, psychological, and ecological features are directly and indirectly linked with diabetes management and treatment results [7]. The development of T2DM is caused by anthropometric (height, weight, percentage body fat, etc.), demographic (age, gender, family income, education, profession, marital status, etc.), and genetic factors. A family history of diabetes is just one of many risk factors for T2DM. Researchers are only beginning to understand the genetics of diabetes.

Scientists have also shown that racial or ethnic groups have a definite higher risk of diabetes than the counterpart. White Caucasian Americans have a lower risk for developing T2DM than Latino and African Americans. People with obesity or overweight have a significant risk of developing T2DM. Four out of 5 people with T2DM have obesity. One of the relations of diabetes with obesity is that fat induces low-grade inflammation all over the body that contributes to diabetes. Extra abdominal fat can alters the body's response to insulin that ultimately causes insulin resistance [8]. With this condition, cells cannot use insulin to process blood sugar out of the blood, resulting in high blood sugar levels. While not everyone with insulin resistance develops diabetes, people with insu- 
lin resistance are at increased risk of T2DM. Taking too much sugary beverages and lemonade can augment the risk of diabetes [9]. Research finding showed that eating a diet of high calorie, beverages, and refined foods significantly increase the risk of T2DM [10]. In the person with obesity, body fat interacts with insulin and other hormones to influence the development of diabetes. Lean muscle mass, which can be increased through exercise and strength training, plays a role in protecting the body against insulin resistance and T2DM [11]. A six-month study of 117 older men and women with abdominal obesity recently demonstrated that a mix of aerobic and resistance training exercises helped to reduce insulin resistance. Insulin and blood sugar balance is affected due to sleep disturbances which increase the demand of insulin on the pancreas. Over time, this can lead to T2DM [12]. A study conducted on 8,992 adults in the first national health and nutrition examination survey and the result showed that over the course of a decade, those who slept less or more were at higher risk for the development of T2DM. The risk of T2DM increases as people get older, especially after the age 45 . That's probably because people tend to exercise less, lose muscle mass and gain weight as they age [13]. But T2DM is also increasing dramatically among children, adolescents and younger adults [14]. A physiological condition where blood sugar level is increased compared to the normal individual but not high enough to be diagnosed as diabetes is termed as pre-diabetes. Left untreated, pre-diabetes can progress to T2DM. Oxidative stress can be caused by smoking as cigarette smoke combines with oxygen and create a stressful condition that damages cells in the body. Also, oxidative stress may be correlated with the higher risk of diabetes. Smoking is connected with the elevated risk of belly fat and abdominal obesity. Abdominal obesity is a well-recognized risk factor for diabetes as it influences the creation of cortisol, a stress hormone that increases blood sugar level. A person with smoking habit tends to have a greater concentration of cortisol level in blood than nonsmokers [15].

According to above information, T2DM may have a significant correlation with socio-demographic features of patients. The purpose of this current study was to analyze the anthropometric and socio-demographic factors and find out their roles on FBS of T2DM patients in Bangladesh. To use these findings in the appropriate field, some life-style modification guidelines may be recommended to improve the quality of life as well as to prevent the incremental glucose level for T2DM patients.

\section{Material and Methods}

Blood samples were collected from 114 patients (70 males and 44 females), age ranging from 30 to 75 years during February-May 2017. Participants were chosen by cluster and stratified sampling in urban and rural areas. According to American Diabetes Association (ADA) criteria, people with FBS equal to or more than $126 \mathrm{mg} / \mathrm{dL}$ were diagnosed with T2DM [16]. All the participants were well informed about the purpose and objective of the study and a written consent was taken from each of them. Every subject filled up a well-structured ques- 
tionnaire form that contains personal, socio-economic, medical, family, and other demographic information. In patients with no formal education, the relevant information was obtained from primary care-givers. The study protocol was approved by the Ethical Review Committee of the respective hospital.

FBS was measured using laboratory kits (Accu-Chek, Roche Diabetes Care, Inc.) and spectrophotometric method. Weight $(\mathrm{kg})$ and height $(\mathrm{m})$ of the respondents have been taken to calculate their body mass index (BMI) (dividing weight by square of height). Those with a BMI of $18.5-25.0 \mathrm{~kg} / \mathrm{m}^{2}$ were classified as normal, while those with a BMI $>25.0 \mathrm{~kg} / \mathrm{m}^{2}$ were classified as obese [16] Physical activity was classified based on daily work, low: activity relating the extension of muscular-skeletal and moving from one place to another place; medium: physical activity sometimes involving an increase in respiratory rate like cleanliness, gardening, building painter etc.; high: activity connecting a highly increased respiratory rate such as manual labor, building labor, porter etc. Economic condition is defined by respective family income, low: $<30$ kilo Bangladeshi taka (KBDT); medium: 30 - 50 KBDT; good: >50 KBDT. Education was categorized into 3 levels: illiterate, $0-12$ years of education and graduate or above.

The SPSS software package, version 23.0 (SPSS Inc., Chicago, IL) was used to analyze the data. Descriptive statistics were calculated for all the variables. Values were expressed as mean \pm SEM. Descriptive data has been given as frequencies and percentages. Comparisons of all parameters were performed by cross table variations and independent sample t-test and ANOVA. Pearson's correlation analysis was performed to find out the correlation of socioeconomic factors with blood glucose levels of T2DM patients. The data was considered to be significant if the $\mathrm{P}$ value is less than 0.05 .

\section{Results}

The socio-demographic and biographic profiles of the patients have been presented in Figure 1. Approximately 50\% (57) of patients were found within an age range of 30 - 45 years. Among all respondents, 61\% (70) were male and 39\% (44) were female. Roughly $80 \%$ (90) patients were found to be obese and most of the patients were educated. Around 50\% respondents were from middle-class family and had the family income between 30 - 50 KBDT. Urban populations were more prone to have DM than the rural population. Physical activity was found low for $50 \%$ type 2 diabetic patients and $67 \%$ patients were the nonsmoker.

It was observed that the mean \pm SEM of age, BMI, family income, and FBS level of the patients were $46.81 \pm 9.98$ years, $26.82 \pm 2.42 \mathrm{~kg} / \mathrm{m}^{2}, 32.95 \pm 14.17$ $\mathrm{KBDT}$, and $218.84 \pm 48.93 \mathrm{mg} / \mathrm{dL}$, respectively. Associations between sociodemographic factors and FBS levels have been shown in Table 1. The present study showed that FBS levels were significantly correlated with the age, education, residential area, physical activity, and other co-morbid diseases of type 2 diabetic patients $(\mathrm{P}<0.05)$. On the other hand gender differences, BMI, average 
family income, smoking habit, life stress, and family history were not significantly correlated with the FBS levels of T2DM patients.

\section{Discussion}

Previous study results showed that older age, higher socio-economic status,
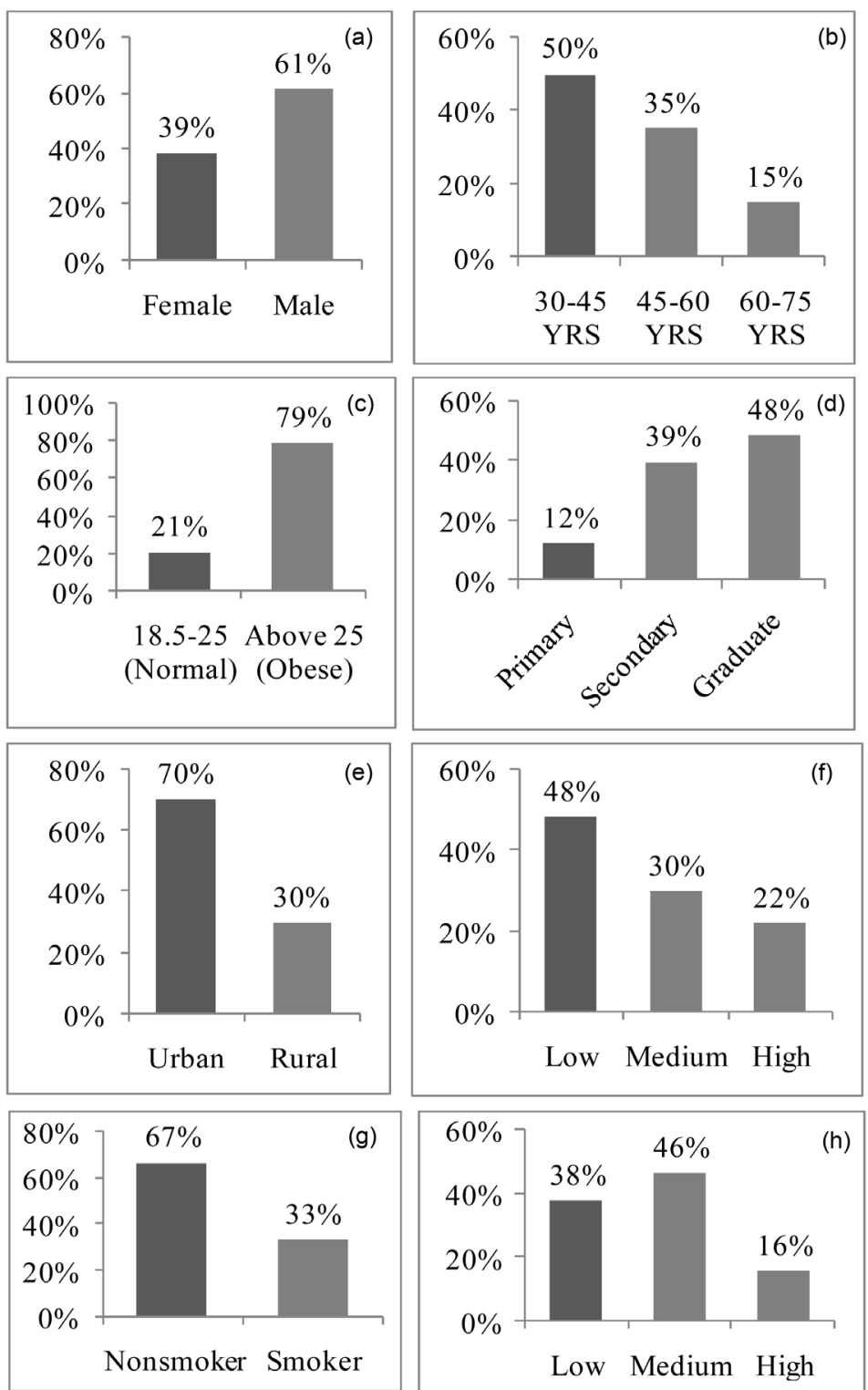

Figure 1. Socio-demographic and biographic profiles of DM patients. Data were analyzed for sex (a); age (b); BMI (c); education (d); residence (e); physical activity (f); smoking habit (g); and economic condition (h). Physical activity was categorized based on activity during daily work, low: activity involving the extension of muscular-skeletal and moving from one place to another place; medium: physical activity sometimes involving an increase in respiratory rate like cleanliness, gardening, building painter etc.; high: activity involving a highly increased reparatory rate such as manual labor, building labor, porter etc. Economic condition is defined by respective family income, low: <30 KBDT; medium: 30 - 50 KBDT; good: >50 KBDT. Abbreviation: BMI, body mass index; YRS, years; KBDT, kilo Bangladeshi taka. 
Table 1. Socio-demographic factors and fasting blood sugar (FBS) levels among type 2 diabetic patients in Bangladesh. $\mathrm{A}{ }^{\star} \mathrm{P}$-value of less than 0.05 was considered statistically significant.

\begin{tabular}{|c|c|c|c|}
\hline Characteristics & $\mathrm{N}$ & Mean $\pm \operatorname{SEM}(\mathrm{mg} / \mathrm{dL})$ & $\mathrm{P}$-value \\
\hline Female & 44 & $211.09 \pm 7.38$ & 0.169 \\
\hline Male & 70 & $224.33 \pm 6.03$ & \\
\hline \multicolumn{4}{|l|}{ Age in years } \\
\hline $30-45$ & 57 & $203.68 \pm 5.12$ & $0.005^{\star}$ \\
\hline $45-60$ & 40 & $221.40 \pm 8.15$ & \\
\hline $60-75$ & 17 & $263.65 \pm 11.44$ & \\
\hline \multicolumn{4}{|l|}{ BMI $\left(\mathrm{kg} / \mathrm{m}^{2}\right)$} \\
\hline 18.5 - 25 (normal) & 24 & $205.50 \pm 10.10$ & 0.133 \\
\hline Above 25 (obese) & 90 & $222.40 \pm 5.10$ & \\
\hline \multicolumn{4}{|l|}{ Education level } \\
\hline Illiterate & 14 & $249.43 \pm 14.22$ & $0.024^{*}$ \\
\hline $1-12$ year education & 45 & $216.80 \pm 6.47$ & \\
\hline Graduate or above & 55 & $212.73 \pm 6.75$ & \\
\hline \multicolumn{4}{|l|}{ Residential area } \\
\hline Urban & 80 & $211.50 \pm 5.56$ & $0.013^{*}$ \\
\hline Rural & 34 & $236.12 \pm 7.32$ & \\
\hline \multicolumn{4}{|l|}{ Physical activity } \\
\hline Low & 55 & $229.58 \pm 6.60$ & $0.021^{*}$ \\
\hline Moderate & 34 & $221.29 \pm 9.50$ & \\
\hline High & 25 & $211.68 \pm 7.93$ & \\
\hline \multicolumn{4}{|l|}{ Economic status } \\
\hline Low & 43 & $223.53 \pm 7.53$ & 0.618 \\
\hline Medium & & $214.30 \pm 6.56$ & \\
\hline Good & 18 & $221.00 \pm 12.41$ & \\
\hline \multicolumn{4}{|l|}{ Smoking habit } \\
\hline Nonsmoker & 76 & $222.87 \pm 5.68$ & 0.216 \\
\hline Smoker & 38 & $210.79 \pm 7.67$ & \\
\hline \multicolumn{4}{|l|}{ Stressful life } \\
\hline Yes & 61 & $218.36 \pm 5.71$ & 0.911 \\
\hline No & 53 & $219.40 \pm 4.40$ & \\
\hline \multicolumn{4}{|l|}{ Family history } \\
\hline Yes & 41 & $219.44 \pm 6.23$ & 0.875 \\
\hline No & 73 & $217.96 \pm 6.71$ & \\
\hline \multicolumn{4}{|l|}{ Other co-morbid disease } \\
\hline Yes & 41 & $259.37 \pm 8.11$ & $0.000^{*}$ \\
\hline No & 73 & $201.70 \pm 4.42$ & \\
\hline
\end{tabular}


higher educational attainment, hypertension, and obesity is significantly correlated with T2DM [17]. Superior socio-economic standing plays a vital role to manage diabetes in the urbanized countries whereas, in Bangladesh, an opposite relation was observed between education level and having diabetes [18]. Insulin resistance and glucose intolerance are occurred due to short-term partial sleep restriction. Men reported that either short or long sleep duration which increases the risk of developing diabetes [19]. Sleep disorder is linked with blood sugar control in African Americans with T2DM [20]. Habitual Chinese dietary pattern is shifting such as high intake of pork, rice, and vegetables are replacing with high intake of edible oil and meats but low consumption of vegetables and cereals. Smoking, breakfast omitting and high intake of sugar-sweetened beverages become very trendy. Inadequate physical activity, sleep duration, and sleep quality are also familiar for Chinese residents, all these are correlated with glucose levels of T2DM [21]. Sitting idle decreases the work performance of large skeletal muscles in legs and back. Over the time course of a single day, physical inactivity may induce negative effects on relatively fast acting cellular processes in the skeletal muscles or other tissues. This may have chronic effects on the propensity to become overweight [22]. The present study also showed that age, education, residential area, physical exercise, and other co-morbid diseases significantly correlated with FBS levels of T2DM patients $(\mathrm{P}<0.05)$.

There is a significant effect of family history of T2DM on individuals with metabolic syndrome as compared to their counterparts in Asian Indian population. The family history of specific diseases reflects the consequences of genetic susceptibility, shared environment and common behaviors [23]. The area of residence has an effect on the level of metabolic control, the occurrence of diabetic complications, and quality of life. The countryside people are considered as a low income and education as well as a high number of persons with the disability [24]. In USA, moderately elevated BMI increases the risk of developing T2DM complications. Obesity is a major contributing factor to T2DM and its complications for both men and women [25]. But the present study results didn't find the association of FBS with sex, BMI, economic condition, smoking habit and family history of patients with T2DM. The limitations of the present study are its small sample size, less homogenous study population, and the inclusion of smokers. The current findings should be considered as preliminary and need further studies for more clarification.

\section{Conclusion}

We found different socio-demographic profiles are significantly correlated with the blood sugar levels of the T2DM patient in Bangladesh. As diabetes is amendable disease, different management guidelines can be produced based on our current study findings. In Bangladesh, need-based diabetes awareness, management, and control policy such as patient education, disease counseling, early diagnosis, and life-style modification techniques should be started among the aged population for better control and care in patients with T2DM. Motiva- 
tional programs (managing blood sugar level, adopting a healthy lifestyle, changing food habits, and reducing body weights) should be implemented.

\section{Consent to Publish}

All study participants or their primary caregivers acknowledged that anonymous data would be published in journal articles.

\section{Availability of Data and Materials}

Data supporting these findings are contained within the manuscript.

\section{Competing Interests}

The authors declare that they have no competing interests.

\section{Acknowledgements}

I am thankful to all the participants who agreed to take part in the study and provided the required information.

\section{References}

[1] American Diabetes Association (2007) Diagnosis and Classification of Diabetes Mellitus. Diabetes Care, 30, S42-S47. https://doi.org/10.2337/dc07-S042

[2] American Diabetes Association (2007) Standards of Medical Care in Diabetes. Diabetes Care, 30, S4-S41. https://doi.org/10.2337/dc07-S004

[3] World Health Organization (2016) Global Report on Diabetes. Geneva. http://apps.who.int/iris/bitstream/10665/204871/1/9789241565257_eng.pdf

[4] International Diabetes Federation (2013) Diabetes Atlas. 6th Edition. https://www.google.com/\#q=International+Diabetes+Federation,+Diabetes+Atlas+ 6 th + Edition +2013

[5] World Diabetic Day 2016. https://www.altiusdirectory.com/Society/world-diabetes-day.php

[6] Dudzinska, M., Tarach, J.S., Zwolak, A., Kurowska, M., Malicka, J., Smolen, A. and Nowakowski, A. (2013) Type 2 Diabetes Mellitus in Relation to Place of Residence: Evaluation of Selected Aspects of Socio-Demographic Status, Course of Diabetes and Quality of Life-A Cross-Sectional Study. Annals of Agricultural and Environmental Medicine, 20, 869-874.

[7] Gonzalez-Zacarias, A.A., Mavarez-Martinez, A., Arias-Morales, C.E., Stoicea, N. and Rogers, B. (2016) Impact of Demographic, Socioeconomic, and Psychological Factors on Glycemic Self-Management in Adults with Type 2 Diabetes Mellitus. Frontiers in Public Health, 4, 195. https://doi.org/10.3389/fpubh.2016.00195

[8] Chiolero, A., Faeh, D., Paccaud, F. and Cornuz, J. (2008) Consequences of Smoking for Body Weight, Body Fat Distribution, and Insulin Resistance. The American Journal of Clinical Nutrition, 87, 801-809.

[9] Stamler, J., Vaccaro, O., Neaton, J.D. and Wentworth, D. (1993) Multiple Risk Factor Intervention Trial Research Group, Diabetes, Other Risk Factors, and 12-yr Cardiovascular Mortality for Men Screened in the Multiple Risk Factor Intervention Trial. Diabetes Care, 16, 434-444. https://doi.org/10.2337/diacare.16.2.434

[10] Teixeira-Lemos, E., Nunes, S., Teixeira, F. and Reis, F. (2011) Regular Physical Exercise Training Assists in Preventing Type 2 Diabetes Development: Focus on Its 
Antioxidant and Anti-Inflammatory Properties. Cardiovascular Diabetology, 10, 12.

[11] (2014) Abstracts from the 37th Annual Meeting of the Society of General Internal Medicine. Journal of General Internal Medicine, 29, 1-545.

[12] Ortega, Á., Berná, G., Rojas, A., Martín, F. and Soria, B. (2017) Gene-Diet Interactions in Type 2 Diabetes: The Chicken and Egg Debate. International Journal of Molecular Sciences, 18, 1188. https://doi.org/10.3390/ijms18061188

[13] Pulgaron, E.R. and Delamater, A.M. (2014) Obesity and Type 2 Diabetes in Children: Epidemiology and Treatment. Current Diabetes Reports, 14, 508. https://doi.org/10.1007/s11892-014-0508-y

[14] American Diabetes Association (2004) Diagnosis and Classification of Diabetes Mellitus. Diabetes Care, 27, S5-S10. https://doi.org/10.2337/diacare.27.2007.S5

[15] Asmat, U., Abad, K. and Ismail, K. (2016) Diabetes Mellitus and Oxidative StressA Concise Review. Saudi Pharmaceutical Journal, 24, 547-553.

[16] World Health Organization (1998) Obesity: Preventing and Managing the Global Epidemic. WHO/NUT/98, Geneva.

[17] Greving, J.P., Denig, P., De Zeeuw, D., Bilo, H.J. and Haaijer-Ruskamp, F.M. (2007) Trends in Hyperlipidemia and Hypertension Management in Type 2 Diabetes Patients from 1998-2004: A Longitudinal Observational Study. Cardiovascular Diabetology, 6, 25. https://doi.org/10.1186/1475-2840-6-25

[18] Chowdhury, M.A.B., Uddin, M.J., Khan, H.M. and Haque, M.R. (2015) Type 2 Diabetes and Its Correlates among Adults in Bangladesh: A Population Based Study. BMC Public Health, 15, 1070. https://doi.org/10.1186/s12889-015-2413-y

[19] Yaggi, H.K., Araujo, A.B. and McKinlay, J.B. (2006) Sleep Duration as a Risk Factor for the Development of Type 2 Diabetes. Diabetes Care, 29, 657-S661. https://doi.org/10.2337/diacare.29.03.06.dc05-0879

[20] Knutson, K.L., Ryden, A.M., Mander, B.A. and Van Cauter, E. (2006) Role of Sleep Duration and Quality in the Risk and Severity of Type 2 Diabetes Mellitus. Archives of Internal Medicine, 166, 1768-1774. https://doi.org/10.1001/archinte.166.16.1768

[21] Zhang, N., Du, S.M. and Ma, G.S. (2017) Current Lifestyle Factors That Increase Risk of T2DM in China. European Journal of Clinical Nutrition, 71, 832-838. https://doi.org/10.1038/ejcn.2017.41

[22] Hamilton, M.T., Hamilton, D.G. and Zderic, T.W. (2007) Role of Low Energy Expenditure and Sitting in Obesity, Metabolic Syndrome, Type 2 Diabetes, and Cardiovascular Disease. Diabetes, 56, 2655-2667. https://doi.org/10.2337/db07-0882

[23] Das, M., Pal, S. and Ghosh, A. (2012) Family history of Type 2 Diabetes and Prevalence of Metabolic Syndrome in Adult Asian Indians. Journal of Cardiovascular Disease Research, 3, 104-108. https://doi.org/10.4103/0975-3583.95362

[24] Dudzinska, W., Lubkowska, A., Jakubowska, K., Suska, M. and Skotnicka, E. (2013) Insulin Resistance Induced by Maximal Exercise Correlates with a Post-Exercise Increase in Uridine Concentration in the Blood of Healthy Young Men. Physiology Research, 62, 163-170.

[25] Gray, B.J., Bracken, R.M., Turner, D., Morgan, K., Thomas, M., Williams, S.P., et al. (2015) Different Type 2 Diabetes Risk Assessments Predict Dissimilar Numbers at "High Risk": A Retrospective Analysis of Diabetes Risk-Assessment Tools. The British Journal of General Practice, 65, e852-e860. https://doi.org/10.3399/bjgp15X687661 
Submit or recommend next manuscript to SCIRP and we will provide best service for you:

Accepting pre-submission inquiries through Email, Facebook, LinkedIn, Twitter, etc. A wide selection of journals (inclusive of 9 subjects, more than 200 journals)

Providing 24-hour high-quality service

User-friendly online submission system

Fair and swift peer-review system

Efficient typesetting and proofreading procedure

Display of the result of downloads and visits, as well as the number of cited articles Maximum dissemination of your research work

Submit your manuscript at: http://papersubmission.scirp.org/

Or contact jdm@scirp.org 